\title{
Numerical simulation of complex tubular joints of Beijing New Airport Terminal C type column
}

\author{
A Zhang $^{1 *}$, G Shangguan ${ }^{1}$, Yanxia Zhang ${ }^{1,2}$, and Dinan Shao ${ }^{1}$ \\ ${ }^{1}$ School of Civil and Transportation Engineering, Beijing University of Civil Engineering and \\ Architecture, Beijing, China \\ ${ }^{2}$ Beijing Higher Institution Engineering Research Center of Civil Engineering Structure and \\ Renewable Material, Beijing University of Civil Engineering and Architecture, Beijing, China
}

\begin{abstract}
The numerical simulation analysis of the two groups of fullscale complex tubular joints of the Beijing New Airport Terminal C type steel column under space static loading tests has been conducted by adopting software ABAQUS. The results obtained from the numerical simulation analysis consistent with those from the tests which enriched the research findings. Based on the research, mechanical performance of the joints has been carried out, the failure modes and ultimate bearing capacity of the joints with no stiffening ribs, three stiffening ribs and five stiffening ribs has been obtained. The numerical simulation results showed that, the bearing capacity of the joints without stiffening ribs were relatively low, the plastic failure of the main pipe was the major form of the destruction and the safety performance were too poor to meet the actual needs of the project. The bearing capacity of the joints significantly improved with the stiffening ribs set inside and the destruction changed to the connection of the main tubular and the branch, which means that the stress of the joints has been obviously improved by the setting of the stiffening ribs and was able to meet the needs of Beijing New Airport Terminal C type column. Through the comparative analysis of the stiffening ribs setting, it can be found that the bearing capacity of the joints were similar between the three and five stiffening ribs, considering the construction difficulty and economic benefits, three stiffening ribs has been selected as the final optimization result.
\end{abstract}

\section{Introduction}

Tubular joints are classified into spatial form and planar form according to their geometric forms. In 2012, Haque [1] et al. conducted experimental research on 12 t-shaped and x-shaped intersecting nodes; Qian [2] et al. proposed in 2013 the stress and deformation formulas of $\mathrm{X}$ - and $\mathrm{k}$-shaped joints of round steel tubes applicable to the nappe analysis of steel truss structures. Subsequently, Qian [3] et al. proposed a new fracture form to describe the ductile tear and brittle fracture failure of circular hollow section joints under monotonic load. Based on the above theoretical research, Qian [4] conducted an experimental study on

\footnotetext{
*Corresponding author: qichengzhi65@163.com
} 
the fracture failure of high-strength steel $\mathrm{x}$-shaped joint under bending force in the plane. Based on the integration theory and test results, Qian [5] established the stress and deformation mechanism of $\mathrm{x}$-shaped and k-shaped joints intersecting each other based on the phenomenon of unstable fracture failure after the ductile crack growth in 2015. In 2013, tong le wei [6] carried out unidirectional static loading on full lap kk-shaped space joints and carried out finite element analysis. Sun Jian-dong and Tong le wei [7] et al. analyzed the domestic and foreign KK space joint form the problem of the calculation formula, which is certified the bearing capacity is not accurate. The same year, Tong le wei [8] [9] and others studied another KT shape space node.

Sui wei ning and Chen yiyi [10] [11] et al. developed a stiffening tubular joint with stiffening plate, and carried out tests and finite numerical simulation on its bearing capacity under compression and tension. Chen Juan, Nie jianguo [12] [13] et al. studied the intersecting joints of concrete filled in the main pipe. Subsequently, they studied the kkshaped tubular concrete intersecting joints once again, carried out uniaxial loading test on the five joints and carried out finite element simulation.

To sum up, at present, the researches on the stiffening mode and the strengthening mode of the intersecting joint mainly focus on pouring concrete and the peripheral sheath plate, most of the steel properties are Q345 series. In addition, due to the limitation of test loading conditions, most of the experimental studies on intersecting joints are carried out in a single or two planes, and there are few studies on the mechanical properties of space joints, especially the complex spatial intersecting joints.

In this paper, based on the existing research of Beijing new airport design and research group, based on the security requirements of the key nodes of c-column in the long-span steel structure system of Beijing new airport terminal, the stiffener design of the nodes is optimized. As the joints are located at the critical position of c-shaped column, the stress is relatively complex. Therefore, the finite element numerical simulation method is adopted in this paper to study the stress performance of the joints, so as to provide technical support for engineering applications.

\section{General conditions of unidirectional static test of the two groups of full-scale complex tubular joints}

The structure of complex steel tubular intersecting joints of terminal c-column is shown in figure 2-1. The node structure shows: branch BG3, BG6 and the crown points and the saddle points of the main tube respectively located on the same plane, branch pipe BG1, BG2, BG4, BG5, BG8 and the crown points and the saddle points of the main tube respectively located on the same plane, the branch BG7, BG9, BG10 and the crown points and the saddle points of the main tube respectively located on the same plane. The difference does not exceed 0.1 times the diameter of the main pipe. Meanwhile, the lower crown points of branch pipes BG3 and BG6 are approximately in the same plane as the upper crown points of branch pipes BG1, BG2, BG4, BG5 and BG8, with a difference of no more than 0.1 times of the main pipe diameter.

In order to study the influence of stiffeners on the stiffness and bearing capacity of joints, two groups of full-length specimens ( 3 in each group) were designed and made without stiffeners, three stiffeners and five stiffeners respectively. The groups of nodes and the size of each part of nodes are shown in table 2-1 and table 2-2. The J1-1 specimens were made of Q345C steel, four pipes were set as the loading end for simultaneous fourpoint loading (hereinafter referred to as four-point loading). For the J1-2 specimens, Q460GJC steel were used. Four pipes were set as the loading end for four-point loading. For the specimens of J1-2 group, the spherical self-balancing omni-directional loading test device was adopted for the test, and the test device is shown in figure 2-2. 
Table 1. Grouping information of full-scale joints

\begin{tabular}{ccccc}
\hline GROUP & $\begin{array}{c}\text { Specimen } \\
\text { number }\end{array}$ & $\begin{array}{c}\text { Node } \\
\text { material }\end{array}$ & $\begin{array}{c}\text { Number of loading } \\
\text { points }\end{array}$ & $\begin{array}{c}\text { Number of } \\
\text { stiffeners }\end{array}$ \\
\hline \multirow{3}{*}{ J1-1 } & J1-1a & Q345C & 4 & - \\
& J1-1b & Q345C & 4 & 3 \\
& J1-1c & Q345C & 4 & 5 \\
J1-2 & J1-2a & Q460GJC & 4 & - \\
& J1-2b & Q460GJC & 4 & 3 \\
& J1-2c & Q460GJC & 4 & 5 \\
\hline
\end{tabular}

Table 2. Size of the components

\begin{tabular}{cccc}
\hline Pipe code & Pipe length $1 / \mathrm{mm}$ & External diameter $\mathrm{D} / \mathrm{mm}$ & Thickness of pipe $\mathrm{t} / \mathrm{mm}$ \\
\hline MG1 & 2215 & 700 & 25 \\
BG1 & 2710 & 402 & 20 \\
BG2 & 2710 & 351 & 16 \\
BG3 & 1360 & 402 & 20 \\
BG4 & 2710 & 402 & 20 \\
BG5 & 2710 & 402 & 20 \\
BG6 & 1360 & 351 & 16 \\
BG7 & 1400 & 299 & 14 \\
BG8 & 800 & 245 & 12 \\
BG9 & 1200 & 299 & 14 \\
BG10 & 1200 & 245 & 12 \\
\hline
\end{tabular}
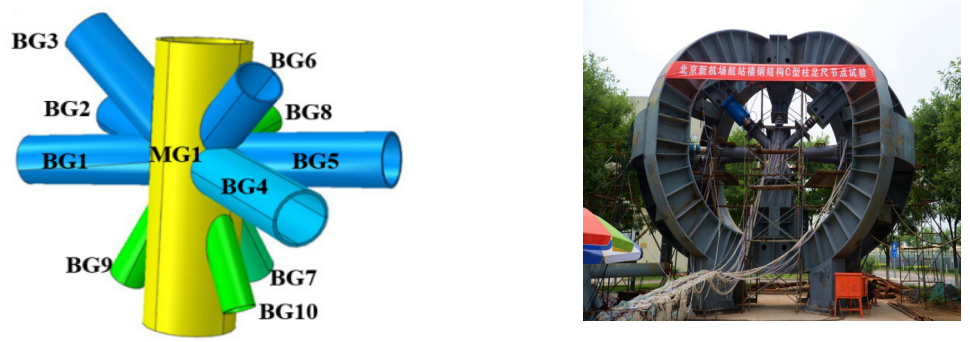

Fig. 1. Finite element models of the two full-scale complex tubular joints

\subsection{Finite element models}

The finite element software ABAQUS was used for numerical simulation of the specimens, which were modeled using the C3D8R solid element. The model size and material properties were consistent with the test specimen.

\subsection{Material properties}

The model components are made of Q345C and Q460GJC steel, and Von Mises yield criterion and follow-up reinforcement criterion are adopted. According to the average value of the material test results, the Elastic modulus is $\mathrm{E}=2.06 \diamond 105 \mathrm{MPa}$, and the Poisson's ratio $=0.3$.In the definition of plastic material parameters in ABAQUS, it is necessary to input the real stress and the real strain in usual conditions. The properties obtained by tensile or 
compressive tests of materials are usually called the nominal stress onom and the nominal strain cnom. Finally, the stress-strain relationship of steel is shown in figure 3-1. In ABAQUS, in order to consider geometric nonlinearity, "Nlgeom" in Step function module should be set as On, so that the influence of large deformation of the structure can be considered in the calculation process.

$$
\begin{gathered}
\varepsilon=\ln \left(1+\varepsilon_{\text {nom }}\right) \\
\sigma=\sigma_{\text {nom }}\left(1+\varepsilon_{\text {nom }}\right)
\end{gathered}
$$

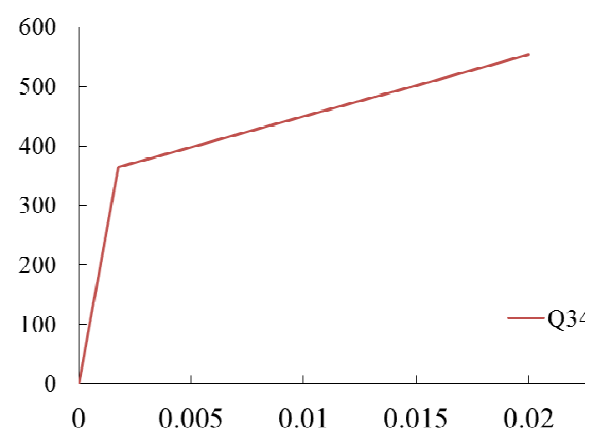

(a) Q345B

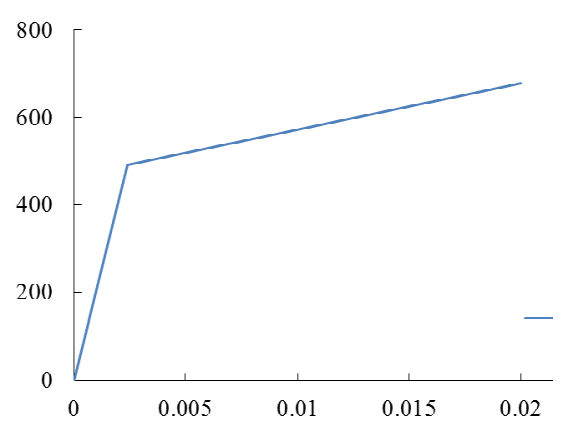

b) Q460GJC

Fig. 2. Material stress-strain curve

\subsection{Boundary conditions and loading process}

Coupling was established at the center of the model loading end, and force was applied at the coupling point. The process of loading is tracked and solved by newton-rafson method. The finite element model is shown in figure 3-2. Model loading adopts monotone hierarchical loading system, and the loading scheme is divided into preloading and formal loading. Taking the design load $\mathrm{Nd}$ as the loading target value, $20 \%$ of the target test load was taken as the preloading, which was completed in two stages of load step.

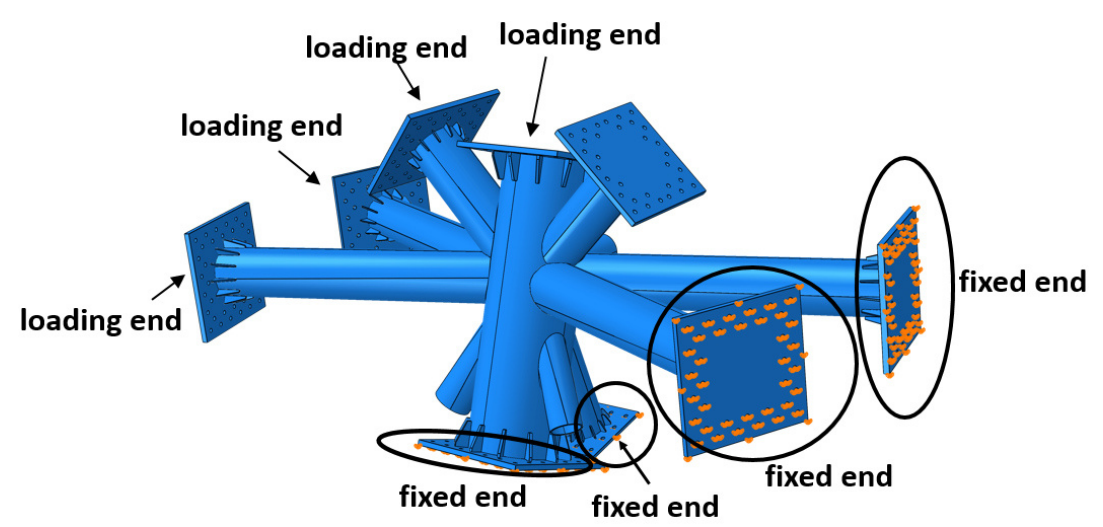

Fig. 3. Finite element model of the specimen 


\section{Comparative analysis of finite element numerical simulation results}

Comparison of axial force - deformation curves of main pipe

Figure 4-1 shows the comparison of the axial force-deformation curves of the six test specimens of J1-1 group and J1-2 group and the finite element models respectively. It can be seen from the figure4-1 that the test values of each specimen are in good agreement with the results of the finite element analysis.

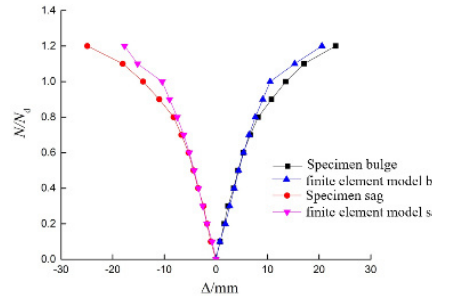

(a) specimen J1-1a

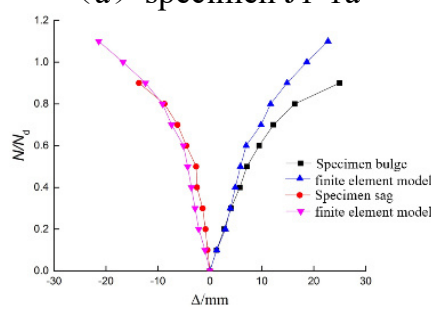

(d) specimen J 1-2a

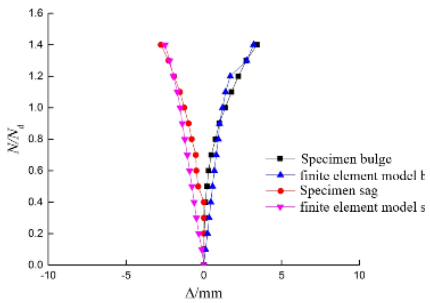

(b) specimen J 1-1b

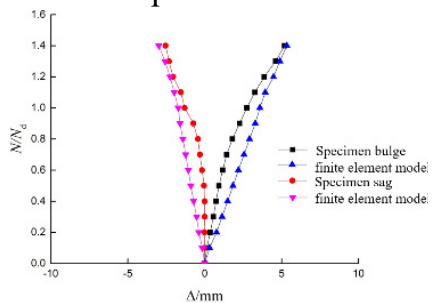

(e) specimen J 1-2b

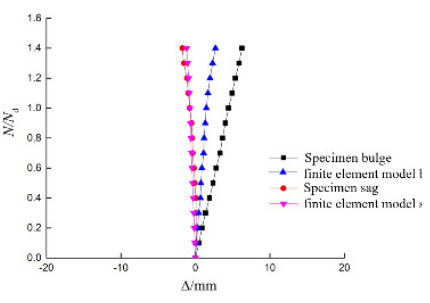

(c) specimen J 1-1c

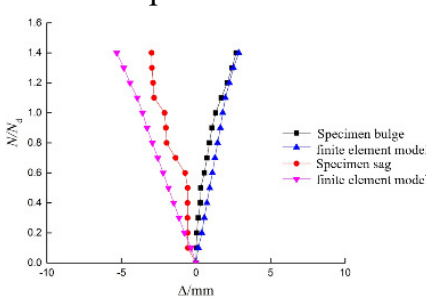

(f) specimen J 1-2c

Fig. 4. Contrast diagram of the relative loading-deformation curve

\section{Comparison of ultimate bearing capacity of nodes}

It can be seen from figure 4-2 and table 4-1 that: 1) the specimens J1-1a and J1-2a all entered the yield state before $1.0 \mathrm{Nd}$ and their bearing capacity was low. At the same time, when the main pipe reaches the ultimate state of bearing capacity, the joint weld appears cracking, indicating that the whole joint is in a completely plastic state.2) setting three stiffeners and five stiffeners can significantly improve the bearing capacity of the joints. From the Angle of improving the stiffness and bearing capacity of the joints, the improvement degree of the two stiffeners is similar.3) due to the low yield strength of Q345C steel, parts of J1-1b and J1-1c joints of the specimen will still enter plastic state in advance even if stiffeners are set.4) under the working condition of ultimate bearing capacity, joints with stiffeners have not fully entered the plastic state and still have certain bearing capacity and deformation capacity, especially the specimens of J1-2. 


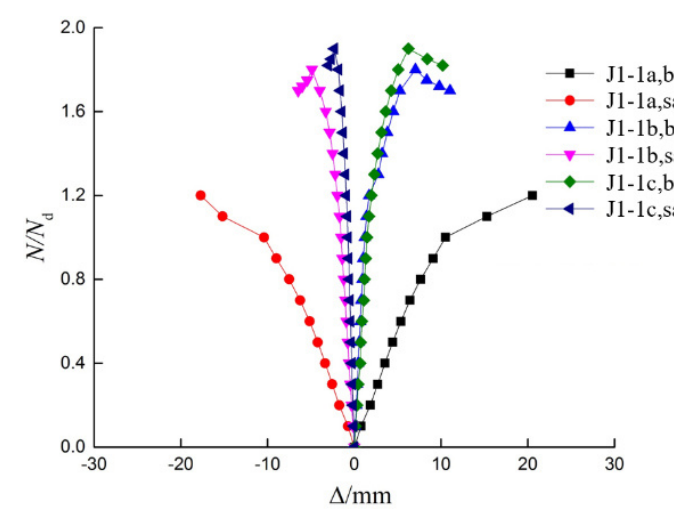

(a) J1-1 specimens

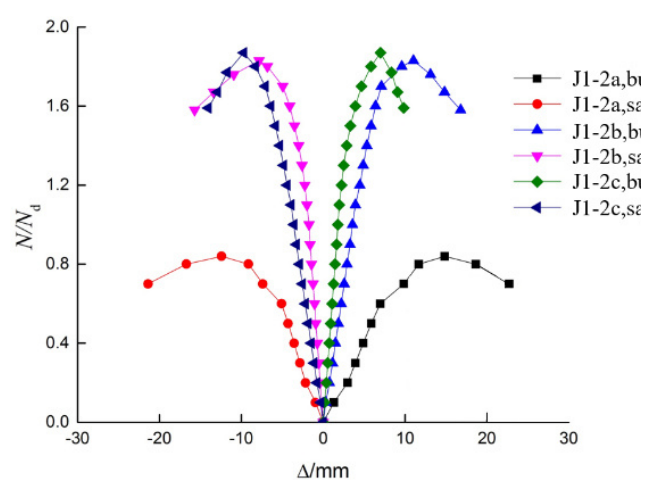

(b) J1-2 specimens

Fig. 5. Contrast diagram of diagram of the FEA loading-deformation curve of each group

Table 3. Contrast diagram of the bearing capacity

\begin{tabular}{cccc}
\hline $\begin{array}{c}\text { Specimen } \\
\text { number }\end{array}$ & Yield load $/ N_{\mathrm{d}}$ & $\begin{array}{c}\text { Ultimate bearing } \\
\text { capacity } / N_{\mathrm{d}}\end{array}$ & Improvement $/ \%$ \\
\hline $\mathrm{J} 1-1 \mathrm{a}$ & 0.8 & 1.2 & - \\
$\mathrm{J} 1-1 \mathrm{~b}$ & 1.2 & 1.8 & 63.6 \\
$\mathrm{~J} 1-1 \mathrm{c}$ & 1.3 & 1.9 & 72.7 \\
$\mathrm{~J} 1-2 \mathrm{a}$ & 0.7 & 0.84 & - \\
$\mathrm{J} 1-2 \mathrm{~b}$ & 1.5 & 1.83 & 117.9 \\
$\mathrm{~J} 1-2 \mathrm{c}$ & 1.5 & 1.87 & 122.6
\end{tabular}

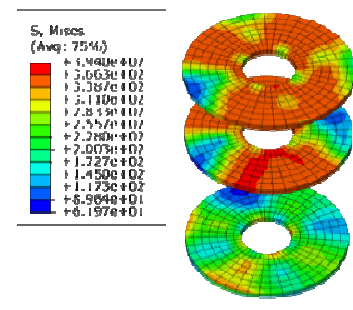

(a) Specimen J1-1b

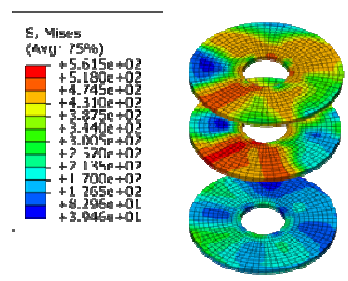

(c) Specimen J1-2b

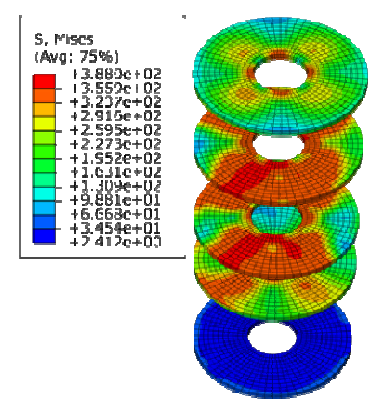

(b) Specimen J1-1c
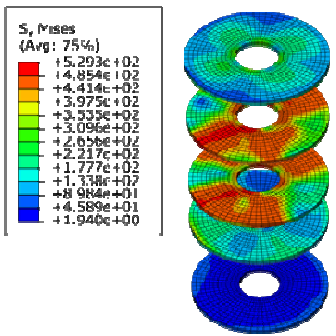

(d) Specimen J1-2c

Fig. 6. Stress nephograms of stiffening ribs under ultimate load 


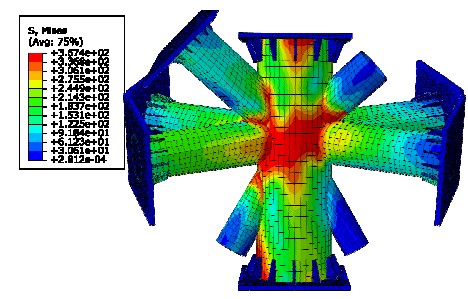

(a) Specimen J1-1a

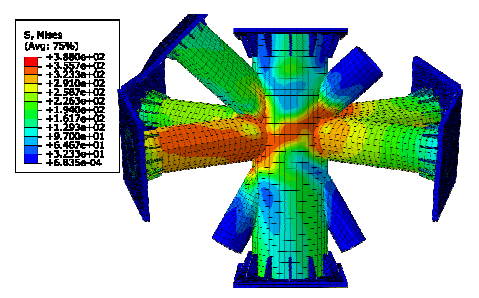

c) Specimen J1-1c

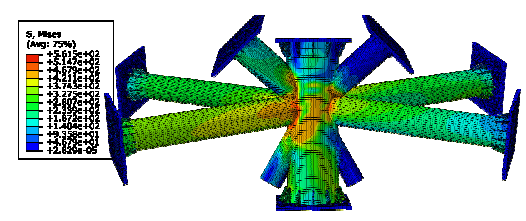

e) Specimen J1-2b

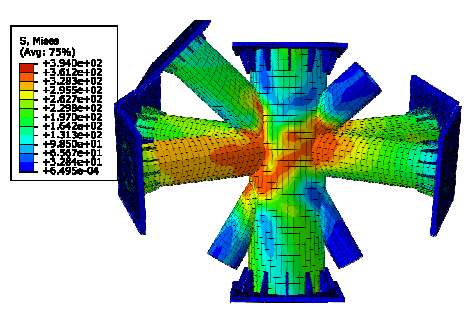

b) Specimen J1-1b

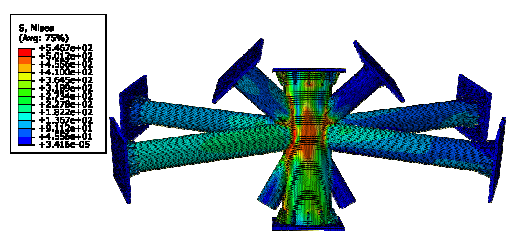

d) Specimen J1-2a

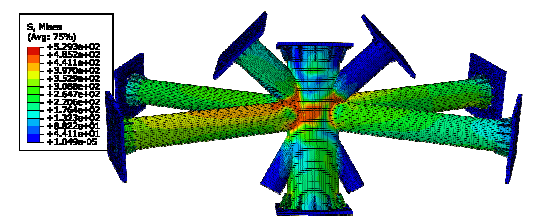

f) Specimen J1-2c

Fig. 7. Stress nephograms of the joints under ultimate load

\section{Comparison of node failure modes}

Force analysis and comparison of loading tube

It can be seen from figure 4-5 that the deformation of loaded branch pipes BG1, BG2 and BG3 firstly increases linearly with the increase of load, and then increases non-linearly with the further increase of load. At the same time, through comparative observation, it can be seen that the deformation of the branch pipe under external load significantly decreases after the stiffening rib is set. 


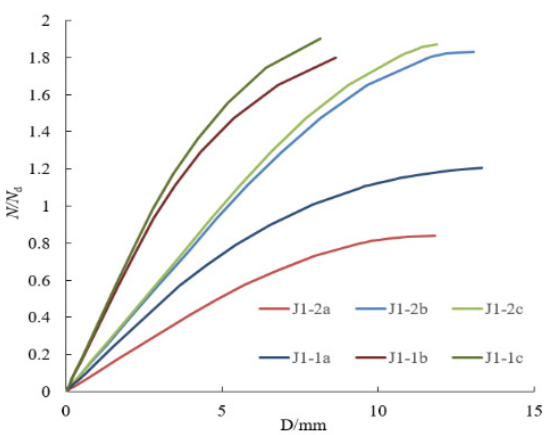

(a) BG1

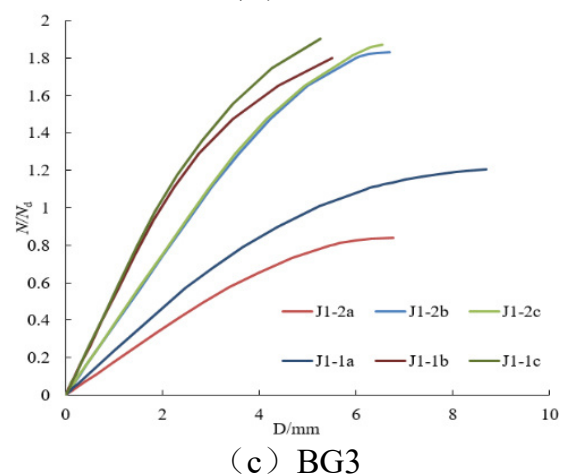

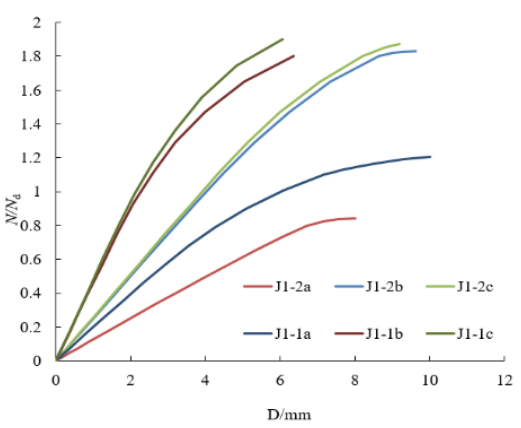

(b) BG2

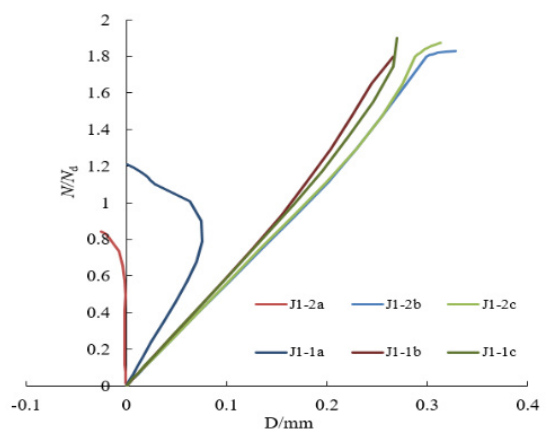

(d) MG1

Fig. 8. FEA results of relative axial force-deformation of each tube

Stress analysis of MG1:

It can be seen form the forces-displacement curve of MG1 in the main pipe that :(1) the sections of branch pipes BG1, BG2 and BG3 are relatively small and subject to large external forces, so their deformation is relatively large; the section of MG1 in the main pipe is large and the external load under working conditions is relatively small, so the axial deformation value of the main pipe is relatively small; (2) in the test, the compressive deformation of the main pipe of $\mathrm{j} 1-1 \mathrm{a}$ and $\mathrm{j} 1-3 \mathrm{a}$ nodes firstly increases and then decreases with the increase of external load; The deformation of $\mathrm{j} 1-2 \mathrm{a}$ joint shows a negative increasing trend with the increase of load, that is, with the gradual increase of the upper pressure of the main pipe, the length of the main pipe increases gradually instead of decreasing due to the presence of pressure. Therefore, for the node without stiffener, the main pipe MG1 stiffness is small, of which the cross-section will produce large concave and convex deformation because of the external load from the branch pipe when the load is bigger, which will produce larger impact on the axial deformation of competent MG1. The axial deformation of MG1 is decided by the impact of branch and external load, and the effect of branch pipe is bigger. (3) For nodes with stiffeners, the axial deformation of MG1 in the main pipe increases with the increase of external load, that is, the axial deformation of MG1 in the main pipe is mainly determined by the external direct load. Therefore, the setting of the stiffener can control the concave and convex deformation and axial deformation of the main pipe MG1, at the same time, reduce the influence of the branch pipe, coordinate the deformation of main pipe, effectively improve the axial stress patterns of main pipe, reduce the effects of the branch pipe stress brought by the internal transfer.(4)For the joints with three stiffeners and five stiffeners, the deformation of the main pipe is similar under other same conditions. 
Table 4. Contrast of force-deformation of each tubes

\begin{tabular}{cccccccc}
\hline Pipe & Load & J1-1a & J1-1b & J1-1c & J1-2a & J1-2b & J1-2c \\
\hline \multirow{4}{*}{ BG1 } & Standard condition & 7.93 & 2.82 & 2.79 & - & 4.85 & 4.67 \\
& Yield load & 5.445 & 3.51 & 4.23 & 8.00 & 8.16 & 7.69 \\
& Ultimate load & 13.33 & 8.63 & 8.14 & 11.83 & 13.07 & 11.89 \\
& Standard condition & 4.27 & 2.08 & 2.10 & - & 3.74 & 3.64 \\
BG2 & Yield load & 6.08 & 2.59 & 3.20 & 6.08 & 6.25 & 6.00 \\
& Ultimate load & 10.00 & 6.35 & 6.08 & 8.00 & 9.62 & 9.18 \\
& Standard condition & 3.65 & 1.81 & 1.86 & - & 2.52 & 2.48 \\
BG3 & Yield load & 5.25 & 2.24 & 2.84 & 4.68 & 4.22 & 4.15 \\
& Ultimate load & 8.69 & 5.51 & 5.27 & 6.78 & 6.68 & 6.55 \\
& Standard condition & 0.08 & 0.16 & 0.17 & - & 0.17 & 0.17 \\
MG1 & Yield load & 0.06 & 0.18 & 0.22 & -0.01 & 0.25 & 0.26 \\
& Ultimate load & 0.00 & 0.27 & 0.27 & -0.02 & 0.33 & 0.31 \\
\hline
\end{tabular}

\section{Stress and strain analysis of main pipe and stiffener}

The maximum stress and equivalent plastic strain value (PEEQ value) of the six joints of two groups and the stiffeners were extracted from the finite element calculation results for stress analysis. It can be seen from the finite element analysis that the maximum stress and strain at the main pipe are located in the middle of the main pipe, while the maximum stress and strain at the stiffener appear at the outer ring of the measuring point in the middle of the main pipe.

It can be seen from the figure that :(1) the plastic development of the main pipe is delayed after the stiffening rib is set, and the maximum stress of the joint under the same working condition and ultimate bearing capacity is reduced;(2) for nodes with stiffeners, the maximum stress and strain of stiffeners are generally higher than the maximum stress and strain of the main pipe under the same working condition, the maximum stress of the stiffeners is $10 \%$ higher than the maximum stress of the main pipe under the same working condition, and the plasticity of the stiffeners appears earlier than the plasticity of the main pipe.

Therefore, it can be seen that the setting of stiffener increases the stiffness of the main pipe, which can effectively reduce the stress level at the main pipe of the node and improve the bearing capacity of the node. At the same time, the stress and the strain of the stiffener is greater than the main pipe, it can be seen from the analysis of the stress and strain of stiffener situation that :stiffener not only can increase the stiffness of the main pipe, but improve the node overall stability with external loads, which acts as a first line of defense. When the plastic energy dissipation began to appear in the stiffener, the main pipe plastic appears later, which protects the main structure. It can be seen from the data in the table4-3, when nodes ultimate bearing capacity is reached, the relative plastic strain of stiffener is bigger and the plastic strain development of the main pipe is relatively small, which shows that the stiffener has been great destroyed can no longer continue to bear the external loads, however the main pipe still has a certain bearing capacity. 


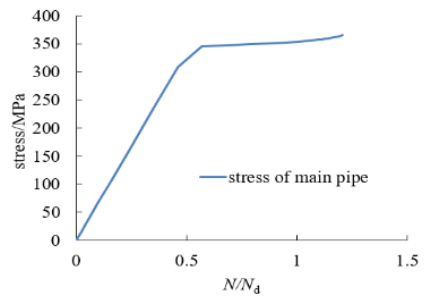

(a) J1-1a

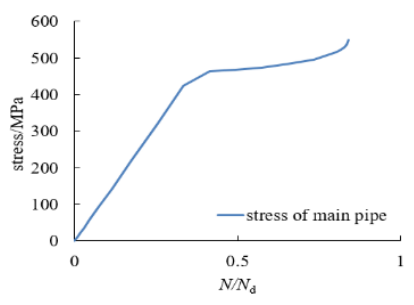

(d) J1-2a

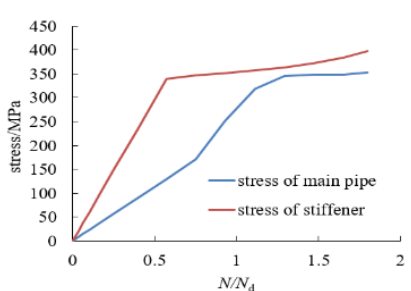

(b) $\mathrm{J} 1-1 \mathrm{~b}$

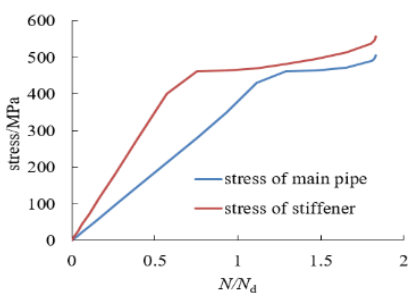

(e) $\mathrm{J} 1-2 \mathrm{~b}$

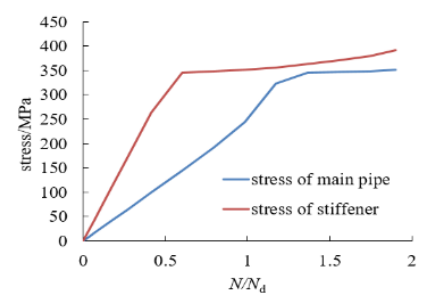

(c) $\mathrm{J} 1-1 \mathrm{c}$

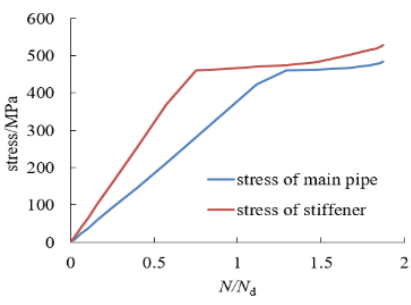

(f) $\mathrm{J} 1-2 \mathrm{c}$

Fig. 9. Stress contrast of the joints

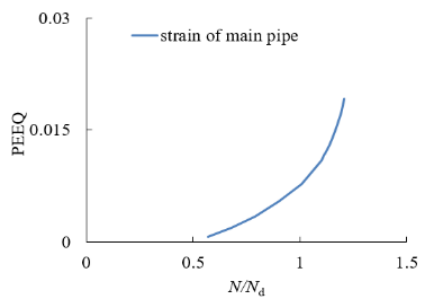

(a) $\mathrm{J} 1-1 \mathrm{a}$

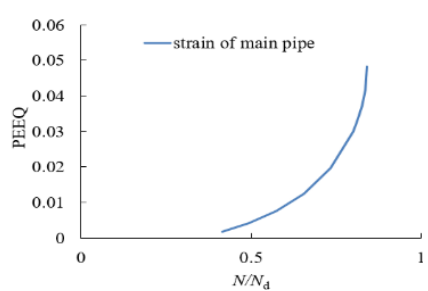

(d) $\mathrm{J} 1-2 \mathrm{a}$

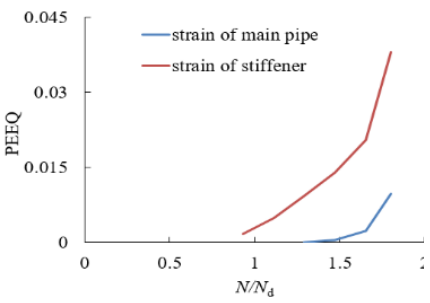

(b) $\mathrm{J} 1-1 \mathrm{~b}$

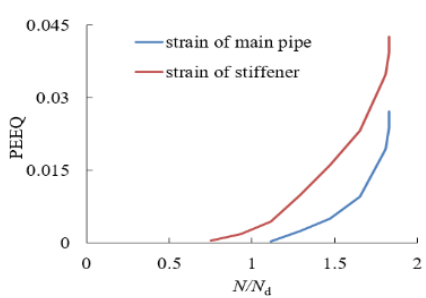

(e) $\mathrm{J} 1-2 \mathrm{~b}$

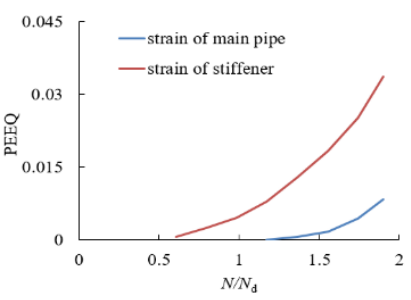

(c) $\mathrm{J} 1-1 \mathrm{c}$

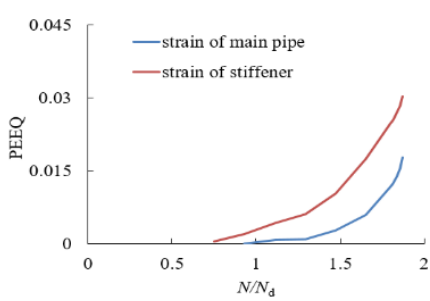

(f) $\mathrm{J} 1-2 \mathrm{c}$

Fig. 10. PEEQ contrast of the joints

Table 5. Comparison of maximum stress and PEEQ on the main tube and stiffening rib

\begin{tabular}{ccccccc}
\hline Specimen number & $\mathrm{J} 1-1 \mathrm{a}$ & $\mathrm{J} 1-1 \mathrm{~b}$ & $\mathrm{~J} 1-1 \mathrm{c}$ & $\mathrm{J} 1-2 \mathrm{a}$ & $\mathrm{J} 1-2 \mathrm{~b}$ & $\mathrm{~J} 1-2 \mathrm{c}$ \\
\hline Maximum stress of main pipe & 364.8 & 352.2 & 351.5 & 548.6 & 505.6 & 485.2 \\
Maximum stress of stiffener & & 397.6 & 392 & & 556.2 & 528.5 \\
Difference value & & $11.42 \%$ & $10.33 \%$ & & $9.10 \%$ & $8.19 \%$ \\
Maximum PEEQ of main pipe & 0.0192 & 0.0097 & 0.0082 & 0.0482 & 0.0271 & 0.0177 \\
Maximum PEEQ of stiffener & & 0.0380 & 0.0336 & & 0.0426 & 0.0303 \\
Difference value & & $74.57 \%$ & $75.44 \%$ & & $36.50 \%$ & $41.56 \%$ \\
\hline
\end{tabular}

Stress and strain analysis at branch pipe 
The maximum stress and equivalent plastic strain (PEEQ) of the six joints of the two groups were extracted from the finite element calculation results for stress analysis. By observing, It can be found from the stress cloud diagram and PEEQ cloud diagram of branch pipes at nodes that:

(1) For nodes J1-1a and J1-1b, during the whole loading process, the maximum stress and PEEQ value at the branch pipe are located at the junction of branch pipe BG1 and MG1; The stress and PEEQ value of J1-1a node are always close to the maximum value of the main pipe, while the stress and PEEQ value of the branch pipe of J1-1b node during the whole loading process are both greater than the maximum value of the main pipe and smaller than the maximum value of the stiffener rib.

(2) For joints J1-2a and J1-2b, the maximum stress at the branch pipe is located at the junction of branch pipe BG4 and main pipe at the initial loading stage. As the external load increases and plasticity begins to appear at various parts of the node, the maximum stress at the branch pipe transfers to the junction of branch pipe BG1 and main pipe MG1.During the whole loading process, the stress and PEEQ value at the main pipe of node J1-2a are always greater than the maximum value at the branch pipe, while the maximum stress and PEEQ value at the branch pipe of $\mathrm{J} 1-2 \mathrm{~b}$ are both greater than the maximum value at the main pipe and less than the maximum value at the stiffening rib.

Therefore, it can be seen that :(1) the branch pipe and main pipe without stiffening rib appears plasticity earlier, while the branch pipe and main pipe with stiffening rib shows better mechanical performance. Therefore, the setting of stiffener can improve the mechanical performance of the branch pipe and main pipe and delay the appearance of plasticity;(2) For the joints without stiffening rib, the maximum stress at the main pipe is close to that at the branch pipe, so the joint failure is mainly manifested as the excessive deformation at the main pipe center and the tear at the junction between the main pipe and the branch pipe, which is consistent with the failure phenomenon in the test. (3) after the stiffener is set, the stress of the main pipe is improved and its stress level is reduced, while the maximum stress and strain value of the branch pipe is between the stiffening rib and the main pipe, so the failure sequence of the joints is: the failure of the stiffening rib -- the failure at the intersection of the main pipe and the branch pipe -- the failure at the center of the main pipe. The failure of a single component occurs before the overall failure of the node, which conforms to the structural design concept. (4) combined with the actual working condition, the internal force of BG1 is the largest, at the early loading stage, the stress of the branch pipe is subjected to adjacent branch pipe to some certain extent, but with the increasing of load, the maximize stress and strain of the main pipe and the branch pipe are located in the junction of main pipe MG1 and branch pipe BG1.

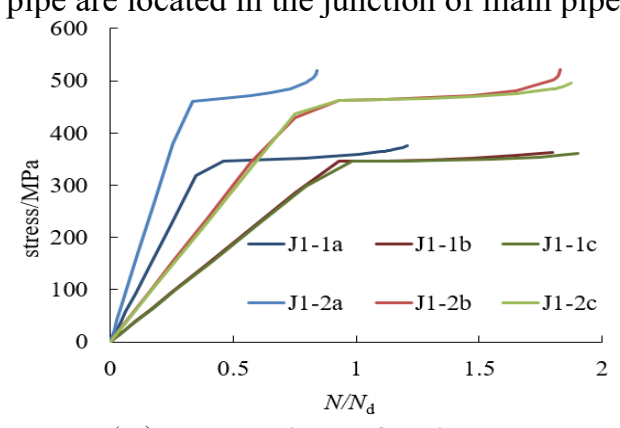

(a) Comparison of node stress

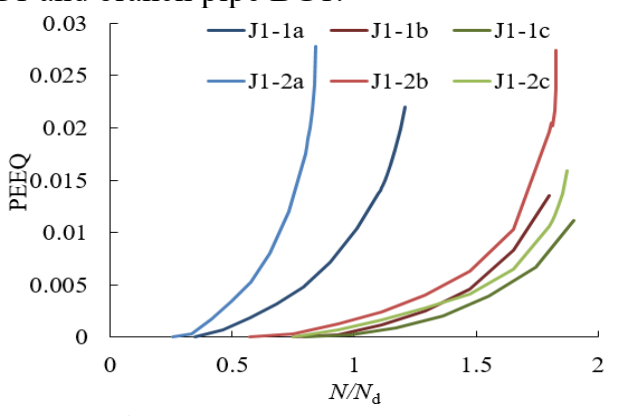

(b) Comparison of node PEEQ

Fig. 8. Stress contrast of the branch tubes 
Table 6. Comparison of maximum stress and PEEQ of branch tubes

\begin{tabular}{|c|c|c|c|c|c|c|}
\hline Component number & $\mathrm{J} 1-1 \mathrm{a}$ & $\mathrm{J} 1-1 \mathrm{~b}$ & $\mathrm{~J} 1-1 \mathrm{c}$ & $\mathrm{J} 1-2 \mathrm{a}$ & $\mathrm{J} 1-2 \mathrm{~b}$ & $\mathrm{~J} 1-2 \mathrm{c}$ \\
\hline Maximum stress of branch pipe & 375.5 & 363.4 & 360 & 518.8 & 521.9 & 495.7 \\
\hline $\begin{array}{l}\text { Difference value compared with main } \\
\text { pipe }\end{array}$ & $2.93 \%$ & $3.18 \%$ & $2.42 \%$ & $-5.45 \%$ & $3.22 \%$ & $2.16 \%$ \\
\hline $\begin{array}{c}\text { Difference value compared with } \\
\text { stiffener }\end{array}$ & & $-8.60 \%$ & $-8.16 \%$ & & $-6.17 \%$ & $-6.21 \%$ \\
\hline Maximum PEEQ of branch pipe & & 0.0136 & 0.0111 & 0.0278 & 0.0274 & 0.0159 \\
\hline $\begin{array}{l}\text { Difference value compared with main } \\
\text { pipe }\end{array}$ & $\begin{array}{c}14.71 \\
\%\end{array}$ & $40.10 \%$ & $35.02 \%$ & $42.27 \%$ & $1.26 \%$ & $10.05 \%$ \\
\hline $\begin{array}{l}\text { Difference value compared with } \\
\text { stiffener }\end{array}$ & & 64.38\% & $66.84 \%$ & & $\stackrel{-}{-}$ & $\stackrel{-}{47.43 \%}$ \\
\hline
\end{tabular}

\section{Conclusion}

(1) Plastic deformation failure of main pipe and deformation failure of welding joint of main branch pipe are the main failure modes of specimens with stiffener, and there was an obvious stress concentration area in the expansion direction of main pipe when the specimens made of Q460GJC steel were destroyed, which was consistent with the test results. The failure mode of specimen with stiffener is the joint failure combining the plastic failure of stiffener and the plastic failure at the connection of main branch pipe.

(2) Since the stiffness of the specimens without setting stiffener, the destruction of the specimen occurs in the joint zone. The destruction of stiffeners will first appears in the internal stiffeners, and then in some branch pipes. The setting of stiffeners changes the failure mode of the specimens and effectively improves the stress situation of the main pipe.

(3) Based on the comprehensive test result and finite element analysis of six specimens of two groups, it can be seen that the joints without stiffeners cannot meet the needs of the actual project, while the mechanical performance of Q460GJC steel joints has been effectively improved after the stiffeners are installed, which can meet the safety performance requirements of the structure and has a large safety reserve. At the same time, the joints with three stiffeners and five stiffeners have similar mechanical characteristics and bearing capacity. Considering the construction difficulty and economic benefits, it is advisable to set three stiffeners in practical projects.

\section{References}

1. Haque T, Packer J A 2012 Elliptical hollow section $T$ and $X$ connections (Canadian Journal of Civil Engineering) 39 (8) pp. 925-936.

2. Qian X, Zhang Y, Choo Y S 2013 A load-deformation formulation for CHS X-and Kjoints in push-over analyses (Journal of Constructional Steel Research) 90 pp. 108119.

3. Qian X, Zhang Y, Choo Y S 2013 A load-deformation formulation with fracture representation based on the $J-R$ curve for tubular joints (Engineering Failure Analysis) 33 pp. 347-366.

4. Qian X, Li Y, Ou Z 2013 Ductile tearing assessment of high-strength steel X-joints under in-plane bending (Engineering Failure Analysis) 28 (2) pp. 176-191. 
5. Qian X, Zhang Y 2015 Translating the Material Fracture Resistance into Representations in Welded Tubular Structures (Engineering Fracture Mechanics) p. 147.

6. Tong Lewei, Sun Jiandong, Wang Bin, Chen Yiyi 2013 Experimental study and numerical analysis on static behavior of multiplanar overlapped CHS KK-joints (Journal of Building Structures) 34 (02) pp. 91-98.

7. Sun Jiandong, Tong Lewei, Wang Bin, Chen Yiyi 2013 Improved formula for loading capacity of multiplanar overlapped CHS KK-joints (Journal of Building Structures) 34 (02) pp. 99-105.

8. Tong Lewei, Sun Jiandong, Wang bin, Chen Yiyi 2013 Static behavior of multiplanar overlapped CHS KT-joints-Part I : experiment, numerical modeling and parametric analysis (CHINA CIVIL ENGINEE RING JOU RNAL) 46 (10) pp.39-47.

9. Sun Jiandong, Tong Lewei, Wang Bin, Chen Yiyi. Static Behavior of Multiplanar Overlapped Chs Kt-Joints 2013 Design Equation (CHINA CIVIL ENGINEE RING JOURNAL) 46 (11) pp. 37-43.

10. Sui Weining, Chen Yiyi, Wang Zhanfei 2012 Numerical Method of Ultimate Capacity of Doubler Plate Reinforced Tubular T-Joints (Journal of Tongji University (Naturl Science) 40 (07) pp. 977-981.

11. Sui Weining, Chen Yiyi, Wang Zhanfei, Zhang Xinlong 2013 Study on Tensile Performance of Doubler Plate Reinforced T-Joints with Circular Chord and Brace (China Civil Engineering Journal) 46 (05) pp. 22-30.

12. Chen Juan, Nie Jianguo, Zhou Chenye 2018 Study On Stress Concentration Factor of Concrete-Filled Steel Tubular T-Joints (Journal of Building Structures) 39 (03) pp. 149-157.

13. Chen Juan, Sun Weijian, Nie Jianguo 2017 Study On Spatial Effect of Concrete-Filled Steel Tubular Kk-Joints (Journal of Building Structures) 38 (S1) pp. 402-408. 